\title{
Mechanism behind gamma band activity in the pedunculopontine nucleus (PPN)
}

\author{
Nebojsa Kezunovic ${ }^{1}$, Francisco J. Urbano ${ }^{2}$, Christen Simon ${ }^{1}$, James Hyde ${ }^{1}$, Kristen \\ Smith $^{1}$, and E. Garcia-Rill ${ }^{1}$ \\ ${ }^{1}$ Center for Translational Neuroscience, Department of Neurobiology and Developmental \\ Sciences, University of Arkansas for Medical Sciences, Little Rock, AR 72205 \\ ${ }^{2}$ IFIBYNE, CONICET, University of Buenos Aires, Buenos Aires, Argentina
}

\section{Abstract}

The pedunculopontine nucleus (PPN), part of the reticular activating system, modulates waking and paradoxical sleep. During waking and paradoxical sleep, EEG responses are characterized by low amplitude, high frequency oscillatory activity in the beta/gamma band range $(\sim 20-80 \mathrm{~Hz})$. We reported that gamma band activity may be intrinsically generated by the membrane electroresponsiveness of PPN neurons, and that the neuronal ensemble generates different patterns of gamma activity in response to specific transmitters. This study attempted to identify the voltage-gated calcium and potassium channels involved in the rising and falling phases of gamma oscillations in PPN neurons. We found that all rat (8-14 day) PPN cell types showed gamma oscillations in the presence of TTX and synaptic blockers when membrane potential was depolarized using current ramps. PPN neurons showed gamma oscillations when voltage-clamped at holding potentials above $-30 \mathrm{mV}$, indicating their origin, we speculate, is spatially located beyond voltage clamp control. The average frequency for all PPN cell types was $23+/-1 \mathrm{~Hz}$, which increased under carbachol $(47+/-2 \mathrm{~Hz}$; ANOVA df $=64, \mathrm{t}=12.5, \mathrm{p}<0.001)$. The N-type calcium channel blocker $\omega$-conotoxin-GVIA partially reduced gamma oscillations, while the P/Qtype blocker $\omega$-agatoxin-IVA abolished them. Both $\omega$-CgTX and $\omega$-Aga blocked voltagedependent calcium currents by $56 \%$ and $52 \%$, respectively. The delayed rectifier-like potassium channel blocker a-dendrotoxin also abolished gamma oscillations. In carbachol-induced PPN population responses, $\omega$-agatoxin-IVA reduced higher, and $\omega$-CgTx mostly lower, frequencies. These results suggest that voltage-dependent P/Q-, and to a lesser extent $\mathrm{N}-$, type calcium channels mediate gamma oscillations in PPN.

\section{Keywords}

arousal; calcium channels; N-type; P/Q-type; gamma band; oscillations

\section{Introduction}

During waking and paradoxical sleep, the EEG shows low amplitude, high frequency activity at gamma frequencies $(\sim 20-80 \mathrm{~Hz})$. Some authors refer to $12-20 \mathrm{~Hz}$ frequencies as beta oscillations, and $30-90 \mathrm{~Hz}$ frequencies as gamma oscillations. Gamma oscillations appear to participate in sensory perception, problem solving, and memory (Eckhorn et al., 1988; Gray and Singer, 1989; Jones, 2007; Phillips and Takeda, 2009; Palva et al., 2009;

Corresponding author: E. Garcia-Rill, PhD, Director, Center for Translational Neuroscience, Department of Neurobiology and Developmental Sciences, University of Arkansas for Medical Sciences, Slot 847, 4301 West Markham St., Little Rock, AR 72205, TEL. 501-686-5167, FAX. 501-526-7928, GarciaRillEdgar@uams.edu. 
Voss et al., 2009), and this coherence may occur at cortical or thalamocortical levels (Singer, 1993; Llinas et al., 1991). The mechanisms behind such activity include the presence of inhibitory cortical interneurons with intrinsic oscillatory activity in the gamma range (Llinas et al., 1991; Steriade, 1999), many of which are electrically coupled (Gibson et al., 1999), as well as of fast rhythmic bursting pyramidal neurons (also electrically coupled) (Cunningham et al., 2004). In the specific thalamocortical (TC) system, P/Q-type voltagegated calcium channels are located in the dendrites of neurons and support gamma band oscillations that modulate membrane depolarization towards action potential threshold (Pedroarena and Llinas, 1997; Luo and Perkel, 1999; Rhodes and Llinas, 2005). These studies identified the roles of different calcium channels during high-frequency oscillations in TC cells using specific calcium channel blockers. We recently reported that, regardless of the cell type, almost all PPN neurons fired at gamma band frequency, but no higher, when subjected to depolarizing steps (Simon et al., 2010). This unique phenomenon was proposed to be due to intrinsic membrane properties of PPN neurons. Because PPN stimulation has been found to potentiate fast $(20-40 \mathrm{~Hz})$ oscillations in thalamocortical neurons and cortical EEG (Steriade et al., 1991), it is important to identify the ion channels involved in the generation of gamma band activity in the PPN. We refer here to $20-60 \mathrm{~Hz}$ frequencies as gamma (instead of beta/gamma) band in order to speak to this seminal finding in vivo. We report that no gamma frequency oscillations were observed in PPN neurons in the presence of $\omega$-Agatoxin, $\omega$-Conotoxin, or $a$-Dendrotoxin, blockers of voltage-gated calcium channels.

Voltage-gated calcium channels play a pivotal role in determining intrinsic properties and synaptic transmission (Llinas and Hess, 1976; Llinas, 1988; Caterall, 1998; Katz and Miledi, 1965). P/Q-type channels (also known as $\mathrm{Ca}_{\mathrm{v}} 2.1$ channels) are present widely in the brain (Hillman et al., 1991; Uchitel et al., 1992). They are located in the dendrites of thalamocortical neurons and support gamma band oscillations (Pedroarenas and Llinas, 1997; Luo and Perkel, 1999; Rhodes and Llinas, 2005), as well as at cortical levels (Llinas et al., 2007; Jones, 2007). N-type calcium channels in the rat auditory brainstem are restricted to the early postnatal period, and are replaced by P/Q-type channels (Iwasaki and Takahashi, 1998).

Immunocytochemical techniques have demonstrated the presence of N-type channels in brainstem structures (Westenbroek et al., 1992). High-voltage gated potassium channels identified in this study (Kv1.1, Kv1.2, and Kv1.6) belong to a class of delayed rectifier-like potassium channels, that are widespread throughout the nervous system, and have many different functions, one of which is, interestingly, the regulation of state transitions and repetitive activity in striatal medium spiny neurons (Shen et al., 2004). The present study was carried out to determine the mechanism(s) behind the manifestation of gamma band activity in PPN neurons.

\section{Methods}

\section{Slice preparation}

Rodent pups aged 8-14 days from adult timed-pregnant Sprague-Dawley rats (280-350g) were anesthetized with ketamine ( $70 \mathrm{mg} / \mathrm{kg}$, I.M.) until tail pinch reflex was absent. This age range was selected due to the developmental decrease in REM sleep of the rat that occurs peak at 14-16 days and continue until $>20$ days, as determined by our previous body of work on the PPN (Garcia-Rill et al., 2008). A second reason for selecting this age range was that our previously published study showed that, in 7-20 day rats recorded at $30^{\circ} \mathrm{C}$, the maximal firing frequency of PPN cells was $\sim 50 \mathrm{~Hz}$ (Simon et al., 2010). However, most studies looking at high frequency oscillations are performed at $35^{\circ} \mathrm{C}$ or higher (Llinas et al., 1991; Pedroarena and Llinas, 1997). We reasoned that younger cells, given the duration of 
the recordings required, could be recorded for longer periods at higher temperatures. In the present study, we did not identify age-related changes in the properties described below. Pups were decapitated and the brain was rapidly removed and cooled in oxygenated sucroseartificial cerebrospinal fluid (sucrose-aCSF). The sucrose-aCSF consisted of (in mM): 233.7 sucrose, $26 \mathrm{NaHCO}_{3}, 3 \mathrm{KCl}, 8 \mathrm{MgCl}_{2}, 0.5 \mathrm{CaCl}_{2}, 20$ glucose, 0.4 ascorbic acid, and 2 sodium pyruvate. Sagittal sections $(400 \mu \mathrm{m})$ containing the PPN were cut and slices were allowed to equilibrate in normal aCSF at room temperature for $1 \mathrm{hr}$. The aCSF was composed of (in mM): $117 \mathrm{NaCl}, 4.7 \mathrm{KCl}, 1.2 \mathrm{MgCl}_{2}, 2.5 \mathrm{CaCl}_{2}, 1.2 \mathrm{NaH}_{2} \mathrm{PO}_{4}, 24.9$ $\mathrm{NaHCO}_{3}$, and 11.5 glucose. Slices were recorded at $37^{\circ} \mathrm{C}$ while perfused $(1.5 \mathrm{ml} / \mathrm{min})$ with oxygenated $\left(95 \% \mathrm{O}_{2}-5 \% \mathrm{CO}_{2}\right) \mathrm{aCSF}$ in an immersion chamber for patch clamp studies containing the following synaptic receptor antagonists: the selective NMDA receptor antagonist 2-amino-5-phosphonovaleric acid (APV, $40 \mu \mathrm{M})$, the competitive AMPA/kainate glutamate receptor antagonist 6-cyano-7-nitroquinoxaline-2,3-dione (CNQX, $10 \mu \mathrm{M})$, the glycine receptor antagonist strychnine $(\mathrm{STR}, 10 \mu \mathrm{M})$, and the specific $\mathrm{GABA}_{\mathrm{A}}$ receptor antagonist gabazine (GBZ, $10 \mu \mathrm{M})$. All experimental protocols were approved by the Institutional Animal Care and Use Committee of the University of Arkansas for Medical Sciences and were in agreement with the National Institutes of Health guidelines for the care and use of laboratory animals.

\section{Whole-cell patch-clamp recordings}

Differential interference contrast optics was used to visualize neurons using an upright microscope (Nikon FN-1, Nikon, USA). Whole-cell recordings were performed using borosilicate glass capillaries pulled on a P-97 puller (Sutter Instrument Company, Novato, $\mathrm{CA}$ ) and filled with either a high- $\mathrm{K}^{+}$intracellular solution, designed to mimic the intracellular electrolyte concentration, of (in $\mathrm{mM}$ ): $124 \mathrm{~K}$-gluconate, $10 \mathrm{HEPES}, 10$ phosphocreatine di tris, 0.2 EGTA, $4 \mathrm{Mg}_{2} \mathrm{ATP}, 0.3 \mathrm{Na}_{2} \mathrm{GTP}$; or a high Cs+/QX-314 intracellular solution (in mM): $120 \mathrm{CsMeSO}_{3}$, 40 HEPES, 1 EGTA, 10 TEA-Cl, 4 Mg-ATP, $0.4 \mathrm{mM}$ GTP, 10 Phosphocreatine, $2 \mathrm{MgCl}_{2}$. Osmolarity was adjusted to $270-290 \mathrm{mOsm}$ and $\mathrm{pH}$ to 7.3 . The pipette resistance was $2-5 \mathrm{M} \Omega$. All recordings were made using a Multiclamp 700B amplifier (Molecular Devices, Sunnyvale, CA) in both current and voltage clamp mode. Analog signals were low-pass filtered at $2 \mathrm{kHz}$, and digitized at $5 \mathrm{kHz}$ using a Digidata-1440A interface and pClamp10 software (Molecular Devices). The recording region was located mainly in the pars compacta in the posterior PPN, immediately dorsal to the superior cerebellar peduncle. This area of PPN has been shown to have the highest density of cells (Ye et al., 2010; Wang and Morales, 2009). Gigaseal and further access to the intracellular neuronal compartment was achieved in a voltage-clamp configuration mode, setting the holding potential at $-50 \mathrm{mV}$ (i.e. near the average resting membrane potential of PPN neurons). Within a short time after rupturing the membrane, the intracellular solution reached equilibrium with the pipette solution without significant changes in either series resistance or membrane capacitance values. Membrane voltage was depolarized from the $-50 \mathrm{mV}$ holding potential to $0 \mathrm{mV}$, in $5 \mathrm{mV}$ steps, without compensating series resistance (ranging 5-12 M $\Omega$ ). The configuration was then changed to current-clamp mode and the membrane potential was then depolarized using either 2 second duration square or ramp current protocols. No significant rundown due to intracellular dialysis of PPN neurons supra- or subthreshold activity was observed during our recording period for all three types of PPN neurons (up to 40 minutes). Voltage-dependent calcium currents were studied using the high- $\mathrm{Cs}^{+} / \mathrm{QX} 314$ pipette solution in the presence of synaptic receptor antagonists and TTX $(3 \mu \mathrm{M})$. Either square wave voltage steps or voltage ramps were used to generate PPN neuronal calcium currents. Fast compensation was used to maintain the series resistance values under $12 \mathrm{M} \Omega$. 


\section{Drug application}

Bath-applied drugs were administered to the slice via a peristaltic pump (Cole-Parmer, Vernon Hills, IL) and a three-way valve system such that solutions reached the slice $1.5 \mathrm{~min}$ after the start of application. The sodium channel blocker tetrodotoxin citrate (TTX, $3 \mu \mathrm{M}$ ) was purchased from Sigma (St. Louis, MO). Channel blockers were purchased from either Peptide International (Pepnet.com) or Alomone labs (Alomone.com). We used $\omega$-agatoxinIVA ( $\omega$-Aga, 100-200 nM), a P/Q-type calcium channel blocker, $\omega$-conotoxin-GVIA ( $\omega$ CgTX, 1.5-2.5 $\mu \mathrm{M}$ ), a N-type calcium channels blocker, a Dendrotoxin (aDTX, $200 \mathrm{nM}$ ), a big conductance calcium-dependent potassium channel blocker, r Charybdotoxin (ChTx-a, 2 $\mu \mathrm{M}), \mathrm{I}_{\mathrm{A}}$ potassium current blocker blood depressing substance I (DBS-I, $5 \mu \mathrm{M}$ ). The effects of carbachol (CAR) on single cell oscillatory activity were studied using $30 \mu \mathrm{M}$ CAR in aCSF extracellular solution containing synaptic blockers and TTX. We used $2 \mathrm{sec}$ duration ramps in current clamp mode to record membrane oscillations in all three PPN cell types. Oscillatory frequency was analyzed using the power spectrum and compared to the frequencies of PPN neurons observed before CAR superfusion using the same $2 \mathrm{sec}$ ramp duration protocol.

\section{Population responses}

To study the oscillatory properties of the PPN neuronal population, we used the local field potential (LFP) recording technique. LFPs reflect both postsynaptic activity across groups of cells that are periodically synchronized and also voltages generated by currents flowing in and out of dendrites. Many studies have demonstrated that LFP recordings of oscillations are not merely an epiphenomenon but instead important for temporal coordination of neural activity (Colgin and Moser, 2010). We used a BSC-1 interface chamber (Automate Sci., Berkeley, CA) and the slice was visualized with a Wild dissection microscope. Recordings at $37^{\circ} \mathrm{C}$ were made with borosilicate glass capillaries pulled to a $1-2 \mu \mathrm{m}$ tip with $1-2 \mathrm{M} \Omega$ resistance and filled with aCSF. Recordings were amplified with a Grass Inst. (Quincy, MA) P511 amplifier, filtered at $1 \mathrm{~Hz}-1 \mathrm{KHz}$, digitized with a Digidata- $1332 \mathrm{~A}$ at a rate of $10 \mathrm{kHz}$, stored on computer hard drive, and averages and power spectra were analyzed using pClamp10 software. The electrode was inserted into the pars compacta in the posterior PPN, with the tip approximately in the middle of the thickness of the slice in order to record from as large a number of neurons as possible. Multiple pre-drug control recordings were carried out to establish a background level of activity. The power spectrum of $20 \mathrm{sec}$ windows of control activity generally consisted of small peaks of activity at $0-5 \mathrm{~Hz}$ and very little, if any, activity at higher frequencies. We then added the non-specific cholinergic agonist carbachol (CAR) to induce activation of the slice, as reported previously (Simon et al., 2010). As previously described, recordings as close as $100 \mu \mathrm{m}$ outside the PPN failed to show CAR-induced population responses. Protocol for the population response experiments was identical except for the application of different calcium channel blockers. Control recordings were taken for 4 min while only synaptic blockers were being perfused (Figure $7 \mathrm{~A}$ and $\mathrm{B}$, yellow lines). Following the 4 minutes of control recordings, CAR was added to the solution with synaptic blockers for 10 minutes (Figures 7A and B, green line). Either $\omega$ Aga or $\omega-\mathrm{CgTx}$ was then added directly to the slice, while the synaptic blockers solution was being perfused. Twenty minutes were allowed before the next 10-minute addition of CAR in order for the specific calcium channel blocker to take effect (Figures 7A and B, red, and blue lines).

\section{Data Analysis}

Off-line analyses were performed using Clampfit software (Molecular Devices, Sunnyvale, CA). Comparisons between groups were carried out using either Student's t-test or one-way ANOVA, with Bonferroni post hoc testing for multiple comparisons, for single cell recordings and population responses, respectively. Power spectra were composed for both 
voltage clamp and current clamp recordings using steps and ramps. Analysis conditions (power spectra) for population responses consisted of $20 \mathrm{~s}$ windows every $1 \mathrm{~min}$ prior to drug application, during the peak effect, and after the agent had washed. A repeatedmeasures ANOVA model was fit for each response using SAS Proc Mixed software (SAS Institute, Inc, Cary, NC), and the Bonferroni test was again employed to control for multiple comparisons. $t$ values and degrees of freedom were reported for all linear regression ANOVAs. Differences were considered significant at values of $\mathrm{p} \leq 0.05$. All results are presented as mean $\pm \mathrm{SE}$.

\section{Results}

A total of 126 PPN neurons were recorded and their responses to depolarizing steps and ramps, in the presence of TTX, determined the voltage dependence of their oscillatory behavior. We first identified PPN neurons by cell type as previously described (Garcia-Rill et al. 2007, 2008; Simon et al. 2010). No differences in average resting membrane potential was observed among PPN neuronal types (type I: $-56 \pm 3 \mathrm{mV}$; type II: $-54 \pm 2 \mathrm{mV}$; type III: $-52 \pm 2 \mathrm{mV}$; one-way ANOVA; $>0.05$ ). We then studied the effects of depolarizing steps and ramps on induced membrane oscillations. This was followed by pharmacological characterization of the channel types responsible for these oscillations. Finally, we ascertained whether the channel blocker effects on population responses, reflected in LFP recordings in the PPN, affected the responses to specific transmitter agonists (Simon et al., 2010).

\section{Depolarizing ramps generated gamma band oscillations in PPN neurons in the presence of TTX}

We tested the hypothesis that, in the presence of TTX and synaptic blockers, the remaining oscillatory activity observed in the PPN neurons during current clamp square pulse depolarization is due to activation of voltage-dependent calcium channels. Due to the extensive activation of potassium channels during depolarization, PPN neurons could not be depolarized beyond $-25 \mathrm{mV}$ using steps. Thus, we chose to use 2-second-long depolarizing current ramps to gradually change membrane potential from resting values up to $0 \mathrm{mV}$. In the presence of synaptic blockers and TTX (see Methods), square pulses generated smaller amplitude gamma oscillations in all three types of PPN neurons (Figure 1A) compared to the amplitude of the oscillations generated by ramps (Figure 1B). A total of 14 type I, 21 type II and 14 type III neurons tested exhibited both low (theta and alpha, 4-12 Hz) frequency and gamma band $(>20 \mathrm{~Hz})$ frequencies. Gamma band oscillations were visible between $-25 \mathrm{mV}$ and $-5 \mathrm{mV}$ somatic membrane voltage range, and were absent at membrane potentials below $-30 \mathrm{mV}$ or above $0 \mathrm{mV}(\mathrm{n}=6)$. All 3 types of PPN neurons exhibited higher power spectrum amplitudes for gamma band oscillations when a depolarizing ramp was used (Figure 1C) compared to square wave steps. Statistical comparisons between gamma band amplitudes using steps vs ramps in type $\mathrm{I}(\mathrm{df}=12, \mathrm{t}=7.8, \mathrm{p}<0.001)$, type $\mathrm{II}(\mathrm{df}=19, \mathrm{t}=-2.3$, $\mathrm{p}<0.05)$, and type III $(\mathrm{df}=13, \mathrm{t}=9.9, \mathrm{p}<0.001)$ revealed significant differences.

All PPN neuronal types presented gamma band oscillations with frequencies ranging from 20 to $60 \mathrm{~Hz}$. However, higher gamma band peak-to-peak amplitudes were observed in gamma band oscillations recorded from type I and III PPN neurons, with type II neurons showing the lowest amplitudes. Figure $2 \mathrm{~A}$ shows a histogram of oscillation amplitudes vs their frequency of occurrence out of the total percentage of all oscillations that corresponded to each PPN neuronal type (bin interval $=1 \mathrm{mV}$, skewed-like distribution). It can be seen that oscillation amplitudes below $4 \mathrm{mV}$ appeared to be $40-50 \%$ of the total amplitude, and were observed mostly in type I and III neurons (Figure 2A). Oscillations of more than $4 \mathrm{mV}$ in amplitude were present in up to $15 \%$ in type III neurons. However, type II neurons showed the largest proportion of low amplitude oscillations, with up to $60 \%$ of the amplitudes below 
$4 \mathrm{mV}$ (Figure 2A). It should be noted that the presence of gamma oscillations in type II neurons, which are known to lack T-type calcium channels, as well as the presence of oscillations at membrane potentials at which T-type channels are inactivated, both suggest that the mechanism of gamma oscillation manifestation in type II cells is independent of Ttype calcium channels. Statistical comparisons between gamma band amplitudes revealed significant differences (ANOVA, F(2, 747)=94; Bonferroni post-hoc test, type I vs. type II, $\mathrm{t}=4.9, \mathrm{p}<0.001$; type I vs. type III, $\mathrm{t}=8.4, \mathrm{p}<0.001$, and type II vs. type III, $\mathrm{t}=13.5, \mathrm{p}<0.001$ ).

Using a voltage-clamp configuration, we determined whether gamma oscillations would be observed when the holding potential was controlled at values from $-30 \mathrm{mV}$ to $-10 \mathrm{mV}$ (using 2 second-long depolarizing steps). Moreover, using voltage-clamp instrumentation, more positive membrane potentials were reached using step function pulses, thus surpassing the $-25 \mathrm{mV}$ limit observed in our previous current-clamp recordings (see responses to square pulses shown in figure 1A). In our initial experiments, the holding potential was set at $-50 \mathrm{mV}$ (close to the observed PPN neuron average resting membrane potential, see above), and depolarizing prolonged voltage steps were applied to reach holding potentials ranging from -50 to $0 \mathrm{mV}$. No clear oscillatory currents were observed at holding potentials below $-30 \mathrm{mV}$ (Figure 2B, left record). However, clear beta/gamma band oscillations were observed in the power spectra at both $-20 \mathrm{mV}$ and $-10 \mathrm{mV}$ holding potentials (Figure 2B, middle and right records, respectively). Power spectra showed clear voltage dependence for a broad range of frequencies including low theta, beta, and gamma band frequencies (Figure 2C). Since our previous data showed gamma oscillatory activity was manifested almost exclusively in the low gamma range (Simon et al., 2010), we limited our analysis to frequencies from 3-60 Hz. The highest gamma band power amplitudes were observed at a $-10 \mathrm{mV}$ holding potential. The same results were observed in 15 different PPN neurons, regardless of neuronal type. The amplitudes of the peaks in the power spectrum were reduced after series resistance compensation (40-60\%; i.e., to reduce any space clamp problems during recordings), suggesting that PPN neuronal oscillatory activity in voltage clamp was generated in neuronal compartments distant from the soma, as previously shown for thalamic neurons (Pedroarena and Llinas, 1997). These authors established, using calcium imaging, that the gamma oscillations indeed originated in the distal dendrites. That is, somatic voltage clamp ramps allow distal calcium and/or potassium channels to open and, therefore, are able to modulate gamma band activity recorded by the somatic pipette. [We chose to use 2-second-long depolarizing current ramps to gradually change membrane potential from resting values up to $0 \mathrm{mV}$.] We suggest, pending calcium imaging studies, that the same may be true for the PPN.

The range of membrane potentials at which gamma oscillations were observed in the PPN overlapped with that of high-threshold voltage-dependent calcium channel activation voltages in cortex and thalamus (Llinas, 1988; Caterall, 1998; Hille, 2001). Therefore, we studied the effects of both $\omega$-agatoxin-IVA ( $\omega$-Aga, a P/Q-type calcium channel blocker, 100-200 nM) and $\omega$-conotoxin-GVIA ( $\omega$-CgTX, a N-type calcium channels blocker, 1.5$2.5 \mu \mathrm{M})$ on total of 34 PPN neurons. Interestingly, the N-type blocker $\omega$-CgTX only reduced gamma band oscillation amplitude and power spectrum (Figure 3A, B), while the P/ Q-type blocker $\omega$-Aga totally abolished them (Figure 3C, D). The direct effect of individual calcium channel blockers was observed in 18 PPN neurons ( $\omega$-CgTX, n=10; $\omega$-Aga, n=8). Moreover, bath pre-application (>30 minutes) of $\omega$-Aga prevented PPN neurons from oscillating at gamma band in another group of cells $(n=8$, data not shown). Furthermore, application of $\omega$-Aga and $\omega$-CgTx together, completely blocked all the oscillations in yet another group of cells $(n=8)$. These results showed that both voltage-dependent N- and P/Qtype calcium channels were mediating the depolarizing phase of gamma band oscillations in the PPN nucleus. However, only P/Q-type channels appeared to be essential for gamma 
oscillation generation. Moreover, voltage clamp results suggested that calcium channels might be located distally to the somata, in PPN dendritic compartments.

We also studied the effects of potassium channel blockers on the repolarizing phase of gamma band oscillations in the PPN. We determined the effects of specific potassium channel blockers on PPN neurons during ramp-induced oscillations: $a$-Dendrotoxin (200 $\mathrm{nM}$ ), a blocker of delayed rectifier-like voltage-gated potassium channels, $r$-Charybdotoxin $(2 \mu \mathrm{M})$, a blocker of big potassium (BK) calcium-dependent potassium channels, and BDS-I $(5 \mu \mathrm{M})$, a blocker of the $\mathrm{I}_{\mathrm{A}}$ current on PPN neurons. a-Dendrotoxin blocked gamma band oscillations ( $\mathrm{n}=6$, Figure 4A, B) induced by $2 \mathrm{sec}$ ramps, indicating that delayed rectifierlike voltage-gated potassium channels (Kv1.1, 1.2 and 1.6) could play a role in mediating the repolarizing phase of the PPN neuronal gamma oscillations. While, r-Charybdotoxin did not block PPN gamma oscillations in another group of cells $(n=4$, Figure $4 C, D)$, it did appear to increase their amplitude and frequency. Based on these results, we assume that, by blocking large potassium outward currents through BK channels, r-Charybdotoxin increased the flow of $\mathrm{K}+$ ions, which, in turn, contributed to higher amplitude and frequency oscillations. BDS-I blocked the $\mathrm{I}_{\mathrm{A}}$ current without affecting the oscillatory properties of PPN neurons ( $\mathrm{n}=2$, data not shown). The oscillations were abolished after 15-20 min of exposure to a-Dendrotoxin, while cells tested under r-Charybdotoxin kept oscillating for over 30 min without a significant decrease in the amplitude of the oscillations.

\section{Characterization of high-threshold calcium channel types present in PPN neurons}

In order to evaluate the subtypes of high-threshold calcium currents present in PPN neurons, both depolarizing voltage square pulses and ramps were employed in combination with high Cesium/QX314 intracellular pipette solution and synaptic receptor blockers (see Methods). High threshold current I-V curves and time course did not change across PPN cell types. Nevertheless, since type I and III cells exhibited the highest amplitude gamma band oscillations, we pursued the characterization of high-threshold calcium channel types in PPN neurons with clear T-type calcium currents (i.e. only present in type I and III neurons) $(\mathrm{n}=23)$. Thus, only a small percentage $(17 \%, \mathrm{n}=4)$ of PPN cells recorded in this experiment exhibited no low threshold calcium currents (i.e. mostly type II neurons). Calcium currents were recorded 2-4 min after gaining access to the neuronal intracellular compartment, to allow proper delivery of intracellular solution into all neuronal compartments thus decreasing space clamp problems. Recording of the calcium currents lasted for more than 30 min without significant rundown. The holding potential was initially clamped at $-70 \mathrm{mV}$ and then depolarized up to $0 \mathrm{mV}$, using square voltage pulses. Calcium currents became visible at a holding potential of $-50 \mathrm{mV}$ and up to $0 \mathrm{mV}$ (Figure 5A). Two consecutive current peak maxima were observed at $-40 \mathrm{mV}$ and $-10 \mathrm{mV}$ holding potentials (Figure 5A, orange and light green records, respectively). The standard I-V curves for type I and type III PPN neurons showed clear peaks at $-40 \mathrm{mV}$ and $-10 \mathrm{mV}$ (Figure $5 \mathrm{~B}, \mathrm{n}=12$ ), while type II neurons exhibited only a peak at $-10 \mathrm{mV}(\mathrm{n}=4$, data not shown). The peak at $-40 \mathrm{mV}$ is known to be mediated by low-threshold, T-type calcium channels (in type I and III PPN cells, Leonard and Llinas, 1990; Kamondi et al., 1992; Takakusaki and Kitai, 1997), while high-threshold calcium currents peaked at $-10 \mathrm{mV}$. Partial overlapping of the curves at holding potentials between -40 and $-10 \mathrm{mV}$ was probably due to consecutive voltageactivation of high-threshold channels and T-type voltage-inactivation.

In order to determine the presence of P/Q- and N-type calcium conductances in charge of oscillatory properties of the different types of PPN neurons, the specific calcium channel blockers $\omega$-Aga (100-200 $\mathrm{nM})$ and/or $\omega$-CgTX $(1.5-2.5 \mu \mathrm{M})$ were utilized during recording of voltage-clamp calcium currents. A maximal effect was usually achieved after $15 \mathrm{~min}$ of superfusion. Rundown of high-threshold current amplitudes was prevented using a single depolarizing pulse protocol (see figure $5 \mathrm{C}$, from a holding of $-70 \mathrm{mV}$ to $-10 \mathrm{mV}$, to 
maximally activate high-threshold calcium currents) applied every $2-4$ min. Both $\omega$-CgTX and $\omega$-Aga reduced high threshold calcium currents $55 \pm 5 \%(\mathrm{n}=6)$ and $52 \pm 4 \%(\mathrm{n}=5)$, respectively (Figure 5C, blue and red lines, respectively). Figure 5D shows the average current density values when type I and type II neurons were depolarized to $-10 \mathrm{mV}$ holding potential, for control (black bar, $\mathrm{n}=23$ ), $\omega-\operatorname{CgTX}$ (blue bar, $\mathrm{n}=6, \mathrm{df}=16, \mathrm{t}=-9, \mathrm{p}<0.001$, compared to control), $\omega$-Aga (red bar, $\mathrm{n}=5, \mathrm{df}=15, \mathrm{t}=14.7, \mathrm{p}<0.001$, compared to control) and $\omega-\mathrm{CgTX}+\omega$-Aga (dashed bar, $\mathrm{n}=3 ; \mathrm{df}=6, \mathrm{t}=-3.9, \mathrm{p}<0.05$ vs $\omega$-CgTX, and $\mathrm{df}=7, \mathrm{t}=-3.3$, $\mathrm{p}<0.05$ vs $\omega$-Aga). A similar blocking effect of $\omega$-CgTX was observed on type II neurons $(\mathrm{n}=2$, data not shown) as it was in type I and II cells. In conclusion, both $\mathrm{N}$ and P/Q-type were present in PPN neurons. Furthermore, total blockade of high-threshold calcium channels showed only a single peak at $-40 \mathrm{mV}$ on PPN cell types I and III ( $\mathrm{n}=3$, data not shown). In conclusion, our results suggest a dual contribution of both channels to the total calcium currents, although, as stated above, P/Q-type channels were necessary while N-type channels merely contributed to these currents.

\section{Effects of carbachol on PPN neuronal oscillations}

In our previous study, we observed that CAR induced high frequency oscillatory activity predominantly in the gamma and theta band ranges (Simon et al. 2010). In the present study, we wanted to determine if CAR $(30 \mu \mathrm{M})$ superfusion had an effect on the frequency of calcium channel-mediated oscillations in single PPN neurons. We used the same $2 \mathrm{sec}$ ramp protocol used in the experiments above to observe the oscillations. We recorded a group of 20 neurons (age 10-13 days), which included all three PPN cell types. Our results showed that CAR bath application was able to significantly increase input resistance (see Table 1), as previously described (Good et al., 2007), while inducing a doubling of the maximum gamma oscillations in the power spectrum (see Table 1). The average oscillation frequency of PPN neurons (age $8-13$ days) was $23+/-1 \mathrm{~Hz}$ when perfused with synaptic blockers and TTX only $(n=42)$. A representative oscillating PPN neuron at this age can be seen in Figure $6 \mathrm{~A}$ ( $2 \mathrm{sec}$ ramp on the left, power spectrum of the same cell on the right). However, when CAR was applied, the average frequency of gamma oscillations was significantly higher (47 $+/-2 \mathrm{~Hz}, \mathrm{n}=20$; ANOVA df $=64, \mathrm{t}=12.5, \mathrm{p}<0.001$ ). An example of these oscillations appears in Figure 6B ( $2 \mathrm{sec}$ ramp of the left, power spectrum on the right). These oscillations were blocked with $\omega$-Agatoxin (data not shown, $n=2$ ). Furthermore, different cell types did not show differential oscillatory frequencies after CAR exposure. Type II cells still showed generally lower amplitude oscillations than type I or III cells (data not shown). Interestingly, analysis of the power spectrum of oscillatory activity of all cells at different frequency ranges (from theta to gamma) showed that CAR significantly reduced the power amplitude at theta $(\mathrm{n}=62, \mathrm{df}=53, \mathrm{t}=-3.75, \mathrm{p}<0.001)$, alpha $(\mathrm{n}=62, \mathrm{df}=57, \mathrm{t}=-3.67$, $\mathrm{p}<0.001)$, and beta frequencies $(\mathrm{n}=62, \mathrm{df}=57, \mathrm{t}=-3.09, \mathrm{p}<0.001)$, while there was no difference in average amplitude of oscillations at gamma frequency $(n=62, d f=64, t=1.35$, $\mathrm{p}=0.26$ ) (Figure 6C).

\section{Population responses}

Population response recordings were used to study the effects of cholinergic input on the population of neurons in the PPN using the cholinergic agonist carbachol (CAR, $50 \mu \mathrm{M})$, in the presence of fast synaptic blockers (APV, $40 \mu \mathrm{M}$; CNQX, 10 $\mu \mathrm{M}$; STR, $10 \mu \mathrm{M}$; and GBZ, $10 \mu \mathrm{M})(\mathrm{n}=4)$. In other studies, CAR induced different frequency oscillations in a concentration- and temperature-dependent manner in the hippocampus (Fellous and Sejnowski, 2000; Dickinson et al., 2003), and PPN (Simon et al., 2010). In this study, the results were similar to those previously reported for CAR without using fast synaptic blockers (Simon et al., 2010). However, we wanted to determine if the specific P/Q-type calcium channel blocker, $\omega$-Aga $(200 \mathrm{nM})$, and specific N-type calcium channel blocker, $\omega$ CgTx $(2 \mu \mathrm{M})$ would affect the CAR-induced PPN population responses. Results showed 
that $\omega$-CgTx significantly reduced LFPs at $3-11 \mathrm{~Hz}(\mathrm{n}=4, \mathrm{df}=11, \mathrm{t}=-4.2, \mathrm{p}<0.01), 12-20 \mathrm{~Hz}$ $(\mathrm{n}=4, \mathrm{df}=11, \mathrm{t}=-3.7, \mathrm{p}<0.05)$, and $30-38 \mathrm{~Hz}(\mathrm{n}=4, \mathrm{df}=11, \mathrm{t}=-4.0, \mathrm{p}<0.01)$, but not at $21-29$ $\mathrm{Hz}$, and 39-47 Hz frequency ranges. Furthermore, $\omega$-Aga significantly reduced LFPs at $12-$ $20 \mathrm{~Hz}(\mathrm{n}=4, \mathrm{df}=11, \mathrm{t}=-4.4, \mathrm{p}<0.01), 21-29 \mathrm{~Hz}(\mathrm{n}=4, \mathrm{df}=11, \mathrm{t}=-5.1, \mathrm{p}<0.01)$, and 39-47 Hz $(\mathrm{n}=4, \mathrm{df}=11, \mathrm{t}=-13.5, \mathrm{p}<0.01)$, but not at $3-11 \mathrm{~Hz}$, or $30-38 \mathrm{~Hz}$ frequency ranges when compared to CAR responses. Data presented above was obtained by analyzing the power spectra of these population responses in the Clampfit program. Figure 7A shows that $\omega-$ CgTx blocked mostly lower frequency oscillations, while majority of higher gamma frequencies were still present after $\omega$-CgTx application. However, $\omega$-Aga (Figure 7B) blocked most of the CAR-induced higher frequency responses (above low theta), suggesting that, as observed in our single cell studies, P/Q-type calcium channel key elements for the generation of gamma band oscillations in the PPN.

Figure 7C, showing the average percent amplitude of CAR-induced population responses after $\omega$-Aga (red square and line, $n=4$ ) and $\omega$-CgTx (blue square and line, $n=4$ ) application in comparison to the initial amplitudes of the response to CAR at specific frequencies. Statistical analysis of population responses presents a particular problem because each response is from a different slice and/or from a different animal, so that peaks are manifested over a range, not at specific, narrow frequencies. Averaging thus shows peaks with large standard deviations for different frequency ranges. For example, Figure 7C shows that the average values for the $30-38 \mathrm{~Hz}$ range had a $\mathrm{p}$ value of 0.058 , and was almost the same as the $39-47 \mathrm{~Hz}$ range, which was statistically different $(\mathrm{p}<0.01)$. The best-fit line for the $\omega$-CgTx responses was a linear fit $(\mathrm{R}=0.85$, line not shown) suggesting a more effective reduction at lower frequencies in comparison to higher frequency responses. The best-fit line for the $\omega$-Aga responses was an exponential decay curve $(\mathrm{R}=0.64)$ showing no effect on CAR responses at 3-11 Hz, but a reduction at the responses at higher frequencies (12-47 $\mathrm{Hz}$ ), corresponding to our single cell recording results.

\section{Discussion}

These results a) confirm the presence of gamma band activity previously reported in PPN neurons (Simon et al. 2010), and b) identify mechanisms underlying the generation of gamma band oscillations in the PPN. It is also the first time that the potential roles of high voltage-activated calcium, and voltage-gated potassium channels have been described in oscillations in PPN cells. There is now little doubt that PPN neurons also have the ability to manifest gamma band activity that is enhanced by carbachol, such as that reported in cortical, thalamic, hippocampal, and cerebellar cells. Moreover, PPN neurons appear to oscillate at gamma band through $\mathrm{P} / \mathrm{Q}-$, and N-type calcium channels, as well as voltagegated, delayed rectifier-like, potassium channels, suggesting that multiple mechanisms may modulate these cells to fire at gamma band frequencies.

Our previous experiments showed that TTX partially blocked gamma oscillations in PPN neurons during current steps (Simon et al., 2010). These steps, however, were unable to drive the membrane potential to sufficiently depolarized levels (above $-30 \mathrm{mV}$ from a holding potential of $-60 \mathrm{mV}$ ), preventing us from detecting these high-threshold oscillations. Additional current was needed to reach the same membrane potential levels using ramps (e.g. due to the associated increment in membrane input resistance; data not shown). Thus, sodium channel-mediated action potentials appear to be responsible for spreading the membrane depolarization needed to open high-threshold calcium channels presumably located in distal PPN dendrites. Consequently, it can be expected that neurons voltageclamped above $-25 \mathrm{mV}$ might show clear oscillatory activity, as we present here. In other words, our present results show that the membrane potential has to reach $\sim-25 \mathrm{mV}$ at the cell body and above for the high-threshold P/Q-type channels to open, presumably in the 
distal dendrites. Indeed, our voltage clamp data indicates that these channels are located on distal dendrites. Although it is impossible to determine the actual membrane potential of the dendrites without actually clamping them (although voltage clamp of small dendrites would lead to rapid dialysis of the intracellular domain), their membrane potentials are possibly much lower than the $-25 \mathrm{mV}$ threshold induced at the soma, due to the accumulated membrane capacitance between the electrode and these dendritic compartments. Indeed, such levels of change in power were partially reduced after series resistance compensation. Therefore, the real threshold for these oscillations is probably much lower and closer to physiological values.

We previously showed that the firing frequency of PPN neurons plateaued at gamma frequency. These results indicate that voltage-gated channels mediate such activity, allowing gamma oscillations to be manifested continuously. The significance of the plateau suggests that, as long as PPN activation is maintained, the cells fire at gamma frequency, and perhaps its targets receive continuous gamma band activation that could cause the manifestation of gamma band activity in those targets. Furthermore, studies on rats showed that a-

Dendrotoxin-sensitive potassium channels have similar, slow inactivating, characteristics as delayed rectifier $\mathrm{K}^{+}$channels, like those in nodose ganglia. It is believed that these channels influence the excitability of rat visceral sensory neurons (Glazenbrook et at,. 2002). Our data show that delayed rectifier-like inactivating voltage-gated potassium channels (Kv1.1, Kv1.2 and Kv1.6), probably located near P/Q- and N-type calcium channels, play a major role in keeping membrane potential excitability at a level that would allow voltage-sensitive calcium channels to be activated. Also, our results show that delayed rectifier-like channels might be involved in membrane potential repolarization of gamma oscillations in the PPN. These results go a long way towards identifying both high voltage-dependent calcium and delayed rectifier-like potassium channels as targets capable of modulating gamma band oscillations in the PPN. How these channels are modulated by transmitter inputs to the PPN remains to be determined. Indeed, dopamine can increase action potential frequency in thalamocortical neurons by inhibiting a-Dendrotoxin-sensitive potassium channels (Govindaiah et al., 2010).

In current ramp recordings, we observed a wide range of gamma frequencies $(18-47 \mathrm{~Hz})$ at the ages recorded, examples of which can be seen in Figure 3 C, D and Figure 4 C, D. This wide range of activity, although it appears to be high, is common in cortical cells. EEG recordings have shown a wide range of frequencies in the gamma band range, as well as in single cell recordings (Steriade et al., 1991). This variability could be caused by different distributions of calcium channels along the dendrites of PPN cells. Also, far away distal dendrites might oscillate at different frequencies compared to those located more proximal to the soma. In our population responses, we report that $\mathrm{N}$-type calcium channel blockers affected mainly the lower range of frequencies (theta to beta), and P/Q-type channel blockers affected mainly higher frequencies (beta to gamma). Our results suggest that these two types of calcium channels both underlie calcium currents during oscillatory activity. Future studies may reveal whether the anatomical location of these channels plays a significant role in the overall oscillatory activity of these neurons. Nevertheless, we have shown that regardless of cell type, all PPN neurons fired maximally in the gamma range (Simon et al., 2010).

In the cortex, several classes of interneurons are capable of sustained oscillatory rhythms, and increase their frequency with membrane depolarization, which may allow coherent activation depending on the level of excitation (Llinas et al., 1991). Such cortical oscillations are generated by the alternating activation of a TTX-sensitive persistent sodium conductance and a delayed potassium rectifier current, similar to those found in type II PPN neurons (Leonard and Llinas, 1990). The lack of LTS currents in type II cells enable these 
neurons to maintain elevated firing levels, and the presence of gamma band oscillations allow these neurons to sustain such activation. In the thalamus and cortex, during brainactive states, there is an increase in acetylcholine release that depolarizes thalamic and cortical neurons, and consequently induces fast oscillations (20-60 Hz) (Steriade, 2004). Interestingly, the most effective stimulation of the PPN for inducing long lasting fast oscillations in thalamocortical cells and modulating the cortical EEG was three short trains at $300 \mathrm{~Hz}$ (Steriade et al., 1991). High frequency activation has been proposed to account for the temporal coherence of sensory perception in thalamocortical and cortical circuits (Singer, 1999; Llinas et al., 2005; Jones, 2007). However, our previous results showed that type I and type III cells also fired at gamma band frequency. Moreover, we found that type I PPN cells exhibited the highest firing frequencies compared to type II and type III, which did not differ from each other (Simon et al., 2010). In the present study, we found that type I and III cells showed higher amplitude oscillations than type II neurons, but all were in the gamma range.

Muscarinic and nicotinic cholinergic receptors are involved in higher cognitive functions including synaptic plasticity and memory known to involve higher frequency oscillations in the gamma range (Von der Kammer et al., 2001). In rat frontal cortex, CAR can induce changes in different signaling pathways, activating phosphoinositide (PI) turnover, translocating protein kinase C (PKC), and stimulating NOS activity (Sterin-Borda et al., 2003). In this study, we observed an increase in the frequency of oscillations of all PPN neurons after carbachol exposure. These results suggest that, at this age range, rat PPN neurons may need substantial stimulation by cholinergic input to reach the gamma band range. It is possible that modulation of the signaling pathways induced by carbachol may be responsible for the increase in average frequency of oscillatory activity.

Our population responses showed that, in the absence of fast synaptic transmission, CAR induced low theta, and beta/gamma oscillations in population response recordings. However, $\omega$-Aga blocked all higher frequency oscillations, leaving only low theta population responses (Figure 7B). This suggests that P/Q-type calcium channels mediate higher frequency oscillations, but perhaps not low frequency rhythms, in the PPN. Furthermore, $\omega-$ CgTx appears to have more effect in blocking the lower frequencies (Figure 7A). These findings suggest that P/Q-type and N-type high-voltage gated calcium channels may be involved in the manifestation and modulation of different frequencies, perhaps opening the way to the development of novel therapeutic avenues for modulating level of arousal. Furthermore, some of the synchronized activity of PPN neurons in the population studies could be explained by the presence of electrical coupling (Garcia-Rill et al., 2007). Studies in neocortex showed that electrical coupling robustly synchronized the firing of interneurons over a wide range of frequencies $(25-80 \mathrm{~Hz})$ using phase response curve calculations (Mancilla et al., 2007). Although the PPN lacks the laminar organization of the cortex or hippocampus, the elements necessary for achieving synchronized activity of the PPN nucleus as a whole are definitely present. Our results clearly show that P/Q-type calcium channels are a major factor in the manifestation of gamma band activity in PPN neurons. The fact that these oscillations were manifested when voltage-clamped at $-25 \mathrm{mV}$ indicates that these channels are located beyond voltage clamp control, probably in distal dendrites, similarly to those in cortical neurons (Llinas et al., 1989, 1991, 2005). We assume that inputs from sensory systems to the PPN arrive at these distal dendrites and cause them to oscillate, as they appear to do so in cortex (Llinas et al., 1989, 1991, 2005). Unlike the cortex, in which only some neuronal types bear these channels, every cell type in the PPN, whether cholinergic, GABAergic or glutamatergic, manifested such gamma band activity. This suggests that all cells are similarly activated by inputs to their dendrites. It must be assumed that, if all cells are similarly induced to oscillate, these oscillations must be relayed by PPN cells within and outside the nucleus. 
That is, the oscillations may reverberate within the PPN as well as to such ascending targets as the parfascicular nucleus, and descending targets as the subcoeruleus nucleus. The question of whether the PPN is a "generator" of gamma band activity or not is not as important as, how does the CNS maintain gamma band activity? Gamma band activity is thought to persist for hundreds of milliseconds or even seconds. How does a circuit maintain such rapid, recurrent activation? Expecting a circuit of, say, 5 or 10 synapses to reliably relay $40 \mathrm{~Hz}$ cycling without failing is unrealistic. Central synapses, even those in primary sensory pathways, hardly follow more than $20 \mathrm{~Hz}$ stimulation. Without the intrinsic properties afforded by rapidly oscillating channels, gamma band activity could not be maintained for long. Thus, the combination of channels capable of fast oscillations and circuitry that involves activating these channels is a more likely scenario for the maintenance of gamma band oscillations. As far as the PPN is concerned, as part of the RAS, we would expect it to be activated by all sensory modalities, and to relay such activation to ascending targets such as the parafascicular to induce cortical synchronization of fast activity, and descending targets such as the subcoeruleus involved in paradoxical sleep signs. It is such dynamic activation in which we would expect the PPN to be involved.

While it is difficult to apply these findings to the human, the PPN has become a target for deep brain stimulation for the treatment of Parkinson's disease (PD) (Mazzone et al., 2010). Recent studies have reported that administration of levodopa to patients induced alpha frequency oscillations in local field potentials/population responses in the PPN, especially during self-paced voluntary movements (Androulidakis et al., 2008). These authors suggested that alpha oscillations in the PPN may represent a physiological pattern of activity. In a more recent study, self-paced movements generated theta and beta frequency activity in the PPN (Tsang et al. 2010). These authors proposed that different frequencies being generated by the PPN were dependent on the presence of dopaminergic medication, since beta desynchronization was observed in the OFF state, but beta synchronization occurred in the ON state. To date, no reports of gamma band activity in the human PPN have been forthcoming, however, our animal studies are in agreement with this proposition. We reported that rat PPN population responses were differentially induced by a cholinergic agonist compared to kainic acid compared to NMDA (Simon et al. 2010). Carbachol induced a dose-dependent increase in beta/gamma activity, kainic acid induced increases at beta and gamma, while NMDA induced increases at theta through gamma frequencies. That is, we concluded that it is the neurotransmitter profile being activated that may modulate the various frequencies being generated by the PPN (Simon et al., 2010). This may become an important issue clinically, either when using medication, deep brain stimulation, or a combination.

These experiments clearly demonstrate the roles of certain $\mathrm{Na}$, $\mathrm{Ca}$, and $\mathrm{K}$ ion channels in the generation of gamma band activity in PPN neurons. While these findings are not new to the cortex, thalamus, hippocampus or cerebellum, they are entirely novel to the PPN. Our findings suggest that intrinsic gamma oscillations are not just the property of cortical and thalamic neurons, but that they also belong to other regions such as the PPN in the RAS. However, the age group of animals used in our recordings (8-14 days) is during the period of the largest developmental changes that occur in rats (the decrease in paradoxical sleep is from 10-30 days, and transmitter changes peak at 14-16 days) (Garcia-Rill et al. 2008). However, future studies could determine if there are differences in oscillatory activity between developing and adult neurons in the rat PPN. We hypothesize that, rather than participating in the temporal binding of sensory events, gamma band activity manifested in the PPN may help stabilize coherence related to arousal, providing a stable activation state during waking and paradoxical sleep. Much work is needed to support this speculation, but the intriguing findings described here certainly provide a starting point for such investigations. 


\section{Acknowledgments}

This work was supported by R01 NS020246, and by core facilities of the Center for Translational Neuroscience supported by P20 RR020146. In addition, Dr. Urbano was supported by FONCyT, Agencia Nacional de Promoción Científica y Tecnológica; BID 1728 OC.AR. PICT 2007-1009, PICT 2008-2019 and PIDRI-PRH 2007. We are indebted to Prof. R. R. Llinas for his enthusiastic and constructive comments on this manuscript.

\section{References}

Androulidakis MS, Mazzone P, Litvak V, Penny NN, Dileone M, Gaynor LMF, Tisch S, Di Lazzaro V, Brown P. Oscillatory activity in the pedunculopontine area of patients with Parkisnson's disease. Exptl Neurol. 2008; 211:59-66. [PubMed: 18282571]

Caterall WA. Structure and function of neuronal $\mathrm{Ca} 2+$ channels and their role in neurotransmitter release. Cell Calcium. 1998; 24:307-23. [PubMed: 10091001]

Colgin LL, Moser E. Gamma oscillations in the hippocampus. Physiology. 2010; 25:319-329. [PubMed: 20940437]

Cunningham MO, Whittington MA, Bibbig A, Roopun A, LeBeau FE, Vogt A, Monyer H, Buhl EH, Traub RD. A role for fast rhythmic bursting neurons in cortical gamma oscillations in vitro. Proc Nat Acad Sci. 2004; 101:7152-7157. [PubMed: 15103017]

Dickinson R, Awaiz S, Whittington MA, Lieb WR, Franks NP. The effects of general anaesthetics on carbachol-evoked gamma oscillations in the rat hippocampus in vitro. Neuropharmacology. 2003; 44:864-872. [PubMed: 12726818]

Eckhorn R, Bauer R, Jordan W, Brosch M, Kruse W, Munk M, Reitbock HJ. Coherent oscillations: a mechanism of feature linking in the visual system? Biol Cyber. 1988; 60:121-130.

Fellous JM, Sejnowski TJ. Cholinergic induction of oscillations in the hippocampal slice in the slow $(0.5-2 \mathrm{~Hz})$, theta $(5-12 \mathrm{~Hz})$ and gamma $(35-70 \mathrm{~Hz})$ bands. Hippocampus. 2000; 10:187-197. [PubMed: 10791841]

Garcia-Rill E, Heister DS, Ye M, Charlesworth A, Hayar A. Electrical coupling: novel mechanism for sleep-wake control. Sleep. 2007; 30:1405-1414. [PubMed: 18041475]

Garcia-Rill E, Charlesworth A, Heister DS, Ye M, Hayar A. The developmental decrease in REM sleep: the role of transmitters and electrical coupling. Sleep. 2008; 31:673-690. [PubMed: 18517037]

Garcia-Rill, E. Sleep and arousal states: reticular activating system. In: Squire, LR.; Bloom, F.; Spitzer, N.; Gage, N.; Albright, T., editors. New Encyclopedia of Neuroscience. Elsevier; Oxford: 2009. p. $137-143$.

Gibson JR, Beierlein M, Connors BW. Two networks of electrically coupled inhibitory neurons in neocortex. Nature. 1999; 402:75-79. [PubMed: 10573419]

Glazenbrook PA, Ramirez AN, Schild J, Shieh C, Doan T, Wible B, Kunze D. Potassium channels Kv1.1, Kv1.2, and Kv1.6 influence excitability of rat visceral sensory neurons. J Physiol. 2002; 541:467-482. [PubMed: 12042352]

Good CH, Bay KD, Buchanan R, Skinner RD, Garcia-Rill E. Muscarinic and nicotinic responses in the developing pedunculopontine nucleus (PPN). Brain Res. 2007; 1129:147-155. [PubMed: 17156760]

Govindaiah G, Wang Y, Cox CL. Dopamine enhances the excitability of somatosensory thalamocortical neurons. Neuroscience 2010. 2010; 170(4):981-991.

Gray CM, Singer W. Stimulus-specific neuronal oscillations in orientation columns of cat visual cortex. Proc Nat Acad Sci. 1989; 86:1698-1702. [PubMed: 2922407]

Hille, B. Ion channels of excitable membranes. Sinaur; Sunderland: 2001.

Hillman D, Chen S, Aung TT, Cherksey B, Sugimori M, Llinas RR. Localization of P-type calcium channels in the central nervous system. Proc Natl Acad Sci. 1991; 88:7076-80. [PubMed: 1651493]

Iwasaki S, Takahashi T. Developmental changes in calcium channel types mediating synaptic transmission in rat auditory brainstem. J Physiol (Lond). 1998; 509:419-442. [PubMed: 9575291] 
Jones EG. Calcium channels in higher-level brain function. Proc Nat Acad Sci. 2007; 104:17903-4. [PubMed: 17989213]

Jouvet-Mounier D, Astic L, Lacote D. Ontogenesis of the states of sleep in rat, cat, and guinea pig during the first postnatal month. Dev Psychobiology. 1970; 2:216-39.

Kamondi A, Williams J, Hutcheon B, Reiner P. Membrane properties of mesopontine cholinergic neurons studied with the whole-cell patch-clamp technique: implications for behavioral state control. J Neurophysiol. 1992; 68:1359-1372. [PubMed: 1359028]

Katz B, Miledi R. The effect of calcium on acetylcholine release from motor nerve terminals. Proc R Soc Lond B Biol Sci. 1965; 161:483-95. [PubMed: 14278409]

Leonard, CS.; Llinas, RR. Electrophysiology of mammalian pedunculopontine and laterodorsal tegmental neurons in vitro: implications for the control of REM sleep. In: Steriade, M.; Biesold, D., editors. Brain Cholinergic Systems. Oxford Science; Oxford: 1990. p. 205-223.

Llinas RR, Hess R. Tetrodotoxin-resistant dendritic spikes in avian Purkinje cells. Proc Natl Acad Sci. 1976; 73:2520-3. [PubMed: 1065905]

Llinas RR. The intrinsic electrophysiological properties of mammalian neurons: insights into central nervous system function. Science. 1988; 242:1654-64. [PubMed: 3059497]

Llinas RR, Sugimori M, Cherksey B. Voltage-dependent calcium conductances in mammalian neurons. The P channel. Ann N Y Acad Sci. 1989; 560:103-11. [PubMed: 2545128]

Llinas RR, Grace AA, Yarom Y. In vitro neurons in mammalian cortical layer 4 exhibit intrinsic oscillatory activity in the 10- to 50-Hz frequency range. Proc Nat Acad Sci. 1991; 88:897-901. [PubMed: 1992481]

Llinas RR, Urbano FJ, Leznik E, Ramírez RR, van Marle HJ. Rhythmic and dysrhythmic thalamocortical dynamics: GABA systems and the edge effect. Trends Neurosci. 2005; 28:325-33. [PubMed: 15927689]

Llinas RR, Soonwook C, Urbano FJ, Hee-Sup S. $\gamma$-Band deficiency and abnormal thalamocortical activity in P/Q-type channel mutant mice. Proc Nat Acad Sci. 2007; 104:17819-24. [PubMed: 17968008]

Luo M, Perkel DJ. Long-range GABAergic projection in circuit essential for vocal learning. J Comp Neurol. 1999; 403:68-84. [PubMed: 10075444]

Mancilla JG, Lewis TJ, Pinto DJ, Rinzel J, Connors BW. Synchronization of electrically coupled pairs of inhibitory interneurons in neocortex. J Neurosci. 2007; 8:2058-73. [PubMed: 17314301]

Mazzone P, Scarnati E, Garcia-Rill E. Commentary: The pedunculopontine nucleus: clinical experience, basic questions and future directions. J Neural Transm. 2010 (epub ahead of print).

Palva S, Monto S, Palva JM. Graph properties of synchronized cortical networks during visual working memory maintenance. Neuroimage. 2009; 49:3257-68. [PubMed: 19932756]

Pedroarena C, Llinas RR. Dendritic calcium conductances generate high-frequency oscillation in thalamocortical neurons. Proc Natl Acad Sci. 1997; 94:724-8. [PubMed: 9012852]

Philips S, Takeda Y. Greater frontal-parietal synchrony at low gamma-band frequencies for inefficient then efficient visual search in human EEG. Int J Psychophysiology. 2009; 73:350-354.

Rhodes PA, Llinas RR. A model of thalamocortical relay cells. J Physiol. 2005; 565:765-81. [PubMed: 15613378]

Shen W, Hernandez-Lopes S, Tkatch T, Held E, Surmeier J. Kv1.2-containing K+ channels regulate subthreshold excitability of striatal medium spiny neurons. J Neurophysiol. 2004; 91:1337-49. [PubMed: 13679409]

Simon C, Kezunovic N, Ye M, Hyde J, Hayar A, Williams DK, Garcia-Rill E. Gamma band unit and population responses in the pedunculopontine nucleus. J Neurophysiol. 2010; 104:463-74. [PubMed: 20463196]

Singer W. Synchronization of cortical activity and its putative role in information processing and learning. Annu Rev Physiol. 1993; 55:349-74. [PubMed: 8466179]

Singer W. Time as coding space? Curr Opin Neurobiol. 1999; 9:189-94. [PubMed: 10322191]

Steriade, M.; McCarley, RW. Brainstem Control of Wakefulness and Sleep. Plenum Press; New York: 1990. 
Steriade M, Curro Dossi R, Pare D, Oakson G. Fast oscillations (20-40 Hz) in thalamocortical systems and their potentiation by mesopontine cholinergic nuclei in the cat. Proc Nat Acad Sci. 1991; 88:4396-4400. [PubMed: 2034679]

Steriade, M. Cellular substrates of oscillations in corticothalamic systems during states of vigilance. In: Lydic, R.; Baghdoyan, HA., editors. Handbook of Behavioral State Control. Cellular and molecular mechanisms. CRC Press; New York: 1999. p. 327-347.

Steriade M. Progress in Brain Research. Acetycholine systems and rhythmic activities during the waking-sleep cycle. Prog Brain Res. 2004; 145:179-96. [PubMed: 14650916]

Sterin-Borda L, Ganzinelli S, Berra A, Borda E. Novel insight into the mechanisms involved in the regulation of the $\mathrm{m} 1$ muscarinic receptor, iNOS and nNOS mRNA levels. Neuropharmachology. 2003; 45:260-269.

Takakusaki K, Kitai ST. Ionic mechanisms involved in the spontaneous firing of tegmental pedunculopontine nucleus neurons of the rat. Neurosci. 1997; 78:771-794.

Tsang EW, Hamani C, Moro E, Mazella F, Poon YY, Lozano AM, Chen R. Involvement of the human pedunculopontine nucleus region in voluntary movements. Neurology. 2010 (epub ahead of print).

Uchitel OD, Protti DA, Sanchez V, Cherkesey BD, Sugimori M, Llinas RR. P- type voltage-dependent calcium channel mediates presynaptic calcium influx and transmitter release in mammalian synapses. Proc Natl Acad Sci. 1992; 89:3330-3. [PubMed: 1348859]

Von der Kammer H, Demiralay C, Andresen B, Albrecht C, Mayhaus M, Nitsch R. Regulation of gene expression by muscarinic acetylcholine receptors. Biochem Soc Symp. 2001; 67:131-140. [PubMed: 11447829]

Wang HL, Morales M. Pedunculopontine and laterodorsal tegmental nuclei contain distinct populations of cholinergic, glutamatergic and GABAergic neurons in the rat. Eur J Neurosci. 2009; 29:340-358. [PubMed: 19200238]

Westenbroek RE, Hell JW, Warner C, Dubel SJ, Snutch TP, Catterall WA. Biochemical properties and subcellular distribution of an N-type calcium channel alpha 1 subunit. Neuron. 1992; 9:10991115. [PubMed: 1334419]

Ye M, Hayar A, Strotman B, Garcia-Rill E. Cholinergic modulation of fast inhibitory and excitatory transmission to pedunculopontine thalamic projecting neurons. J Neurophysiol. 2010; 103:24172432. [PubMed: 20181729] 

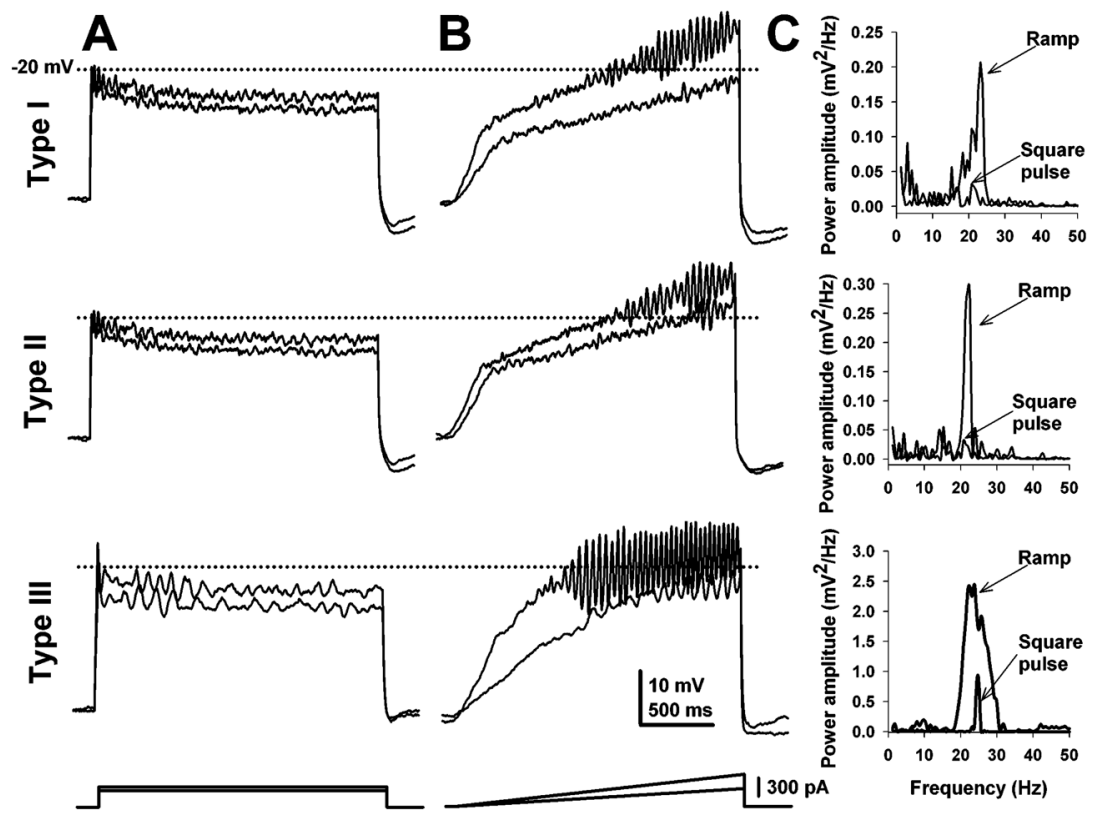

Figure 1. All PPN neuron types exhibited gamma band oscillations when depolarized A) Representative membrane potential responses to depolarizing 2 sec square pulses obtained in the presence of synaptic blockers and TTX in type I (top records), type II (middle records) and type III (bottom records) PPN neurons. B) Representative membrane potential responses to depolarizing 2 sec-long ramps for the same neurons shown in A. C) Overlapping curves comparing power spectrum amplitudes for oscillations obtained using square pulses vs. ramps. All PPN neurons were recorded in current-clamp configuration combining high- $\mathrm{K}^{+}$intracellular solution and synaptic blockers + TTX (see Methods). The respective resting membrane potentials were $-48 \mathrm{mV},-49 \mathrm{mV}$ and $-51 \mathrm{mV}$ for these type I, II and III neurons. 


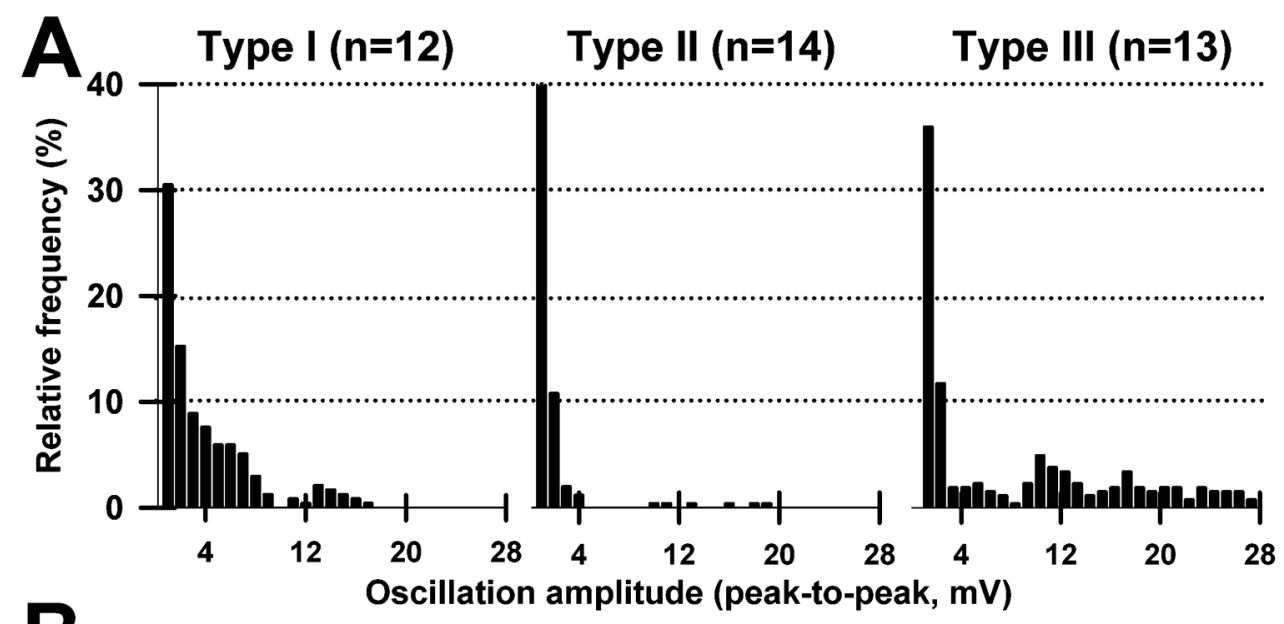

B

Holding $-30 \mathrm{mV}$

Holding $-20 \mathrm{mV}$

Holding $-10 \mathrm{mV}$

monlushumpunhurh

C

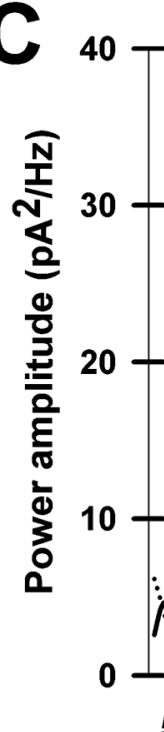

40
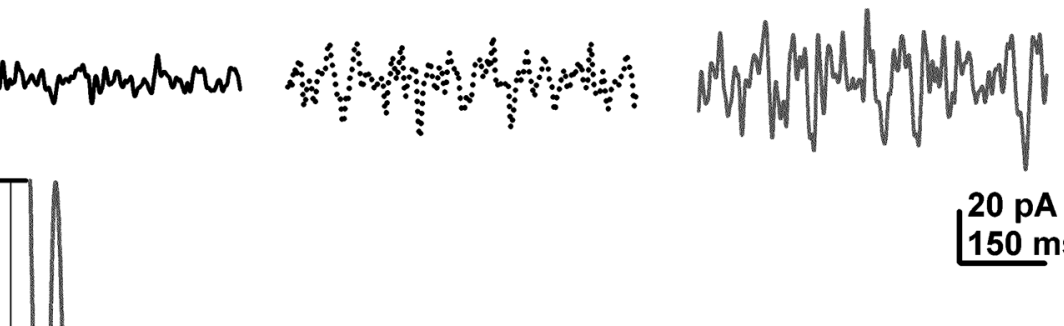

$150 \mathrm{~ms}$

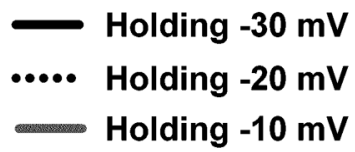

Figure 2. PPN neurons exhibited gamma oscillations under both current and voltage clamp recording configurations

A) Histogram of the relative frequencies (in percentage) of gamma band oscillation amplitudes recorded from type I (left histogram), type II (middle histogram) and type III PPN neurons (right histogram) using 2 sec current clamp ramps. B) Representative current records obtained from PPN neurons voltage-clamped to holding potentials of $-30 \mathrm{mV}$ (left record), $-20 \mathrm{mV}$ (middle record), and $-10 \mathrm{mV}$ (right record). C) Power spectra corresponding to the recordings shown in B. Note the increase in power of several frequencies at $-10 \mathrm{mV}$. Both current and voltage-clamp recordings were performed combining high- $\mathrm{K}^{+}$intracellular solution and synaptic blockers + TTX. 
A
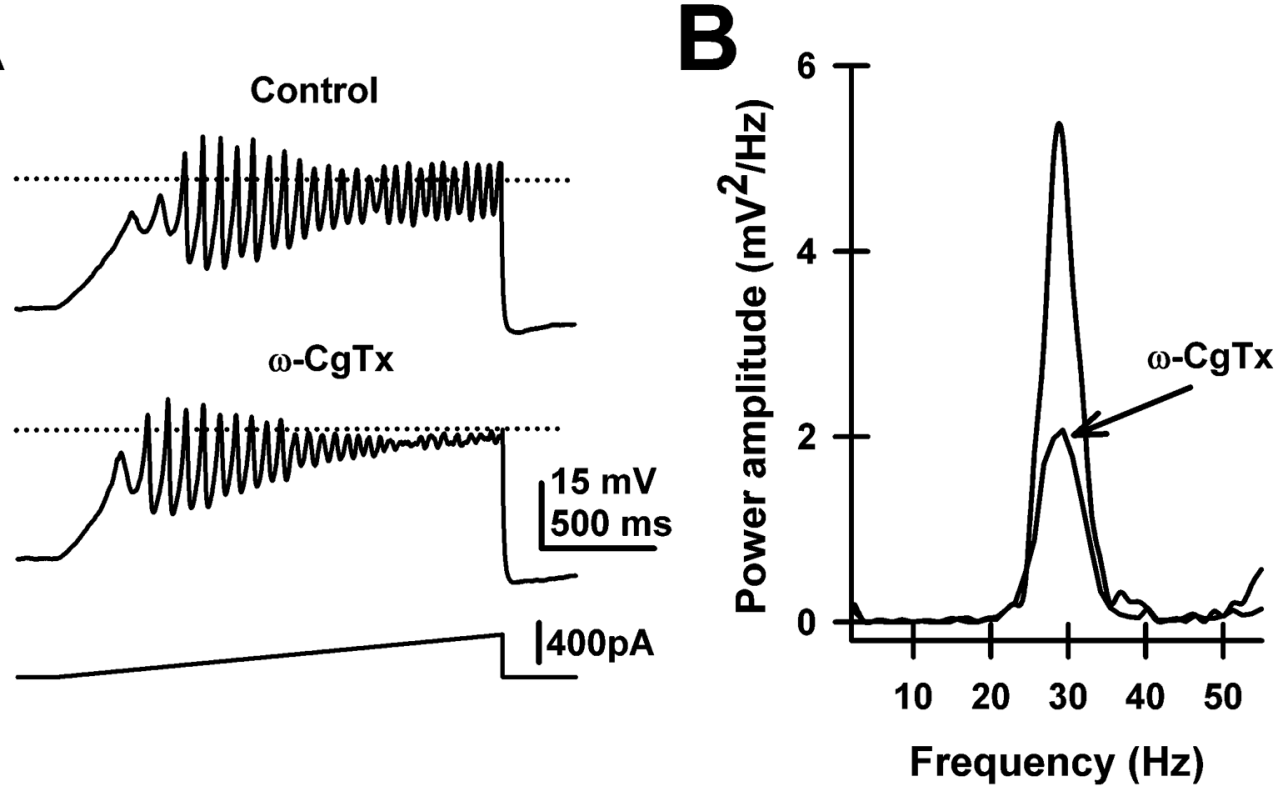

6
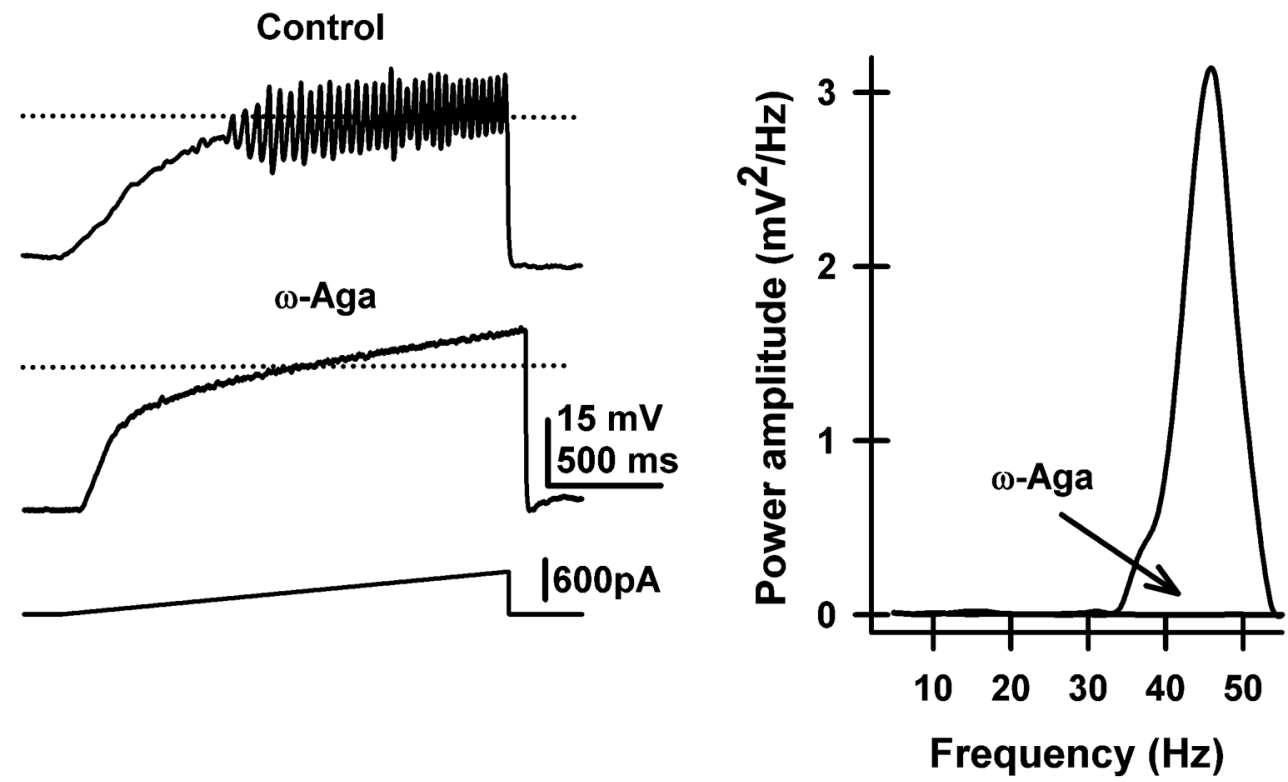

Figure 3. $\mathrm{N}$ - and P/Q-type calcium channels mediated the depolarizing phase of gamma band oscillations in the PPN

A\&B) Representative membrane potential oscillations (A) and power spectrum (B) obtained using 2 sec-long ramps before (top record), and after bath application of $\omega$-CgTX $(2.5 \mu \mathrm{M}$; bottom record). Note the reduction of the amplitude of the oscillations after perfusion with the N-type channel blocker $\omega$-CgTX. C\&D) Representative membrane potential oscillations (C) and power spectrum (D) obtained using 2 sec-long ramps before (top record), and after bath application of $\omega$-Aga (200 $\mathrm{nM}$; bottom record). Note the elimination of oscillations by the P/Q-type channel blocker $\omega$-Aga. Resting membrane potentials were $-48 \mathrm{mV}$ and -52 $\mathrm{mV}$ for panels $\mathrm{A}$ and $\mathrm{C}$, respectively. 

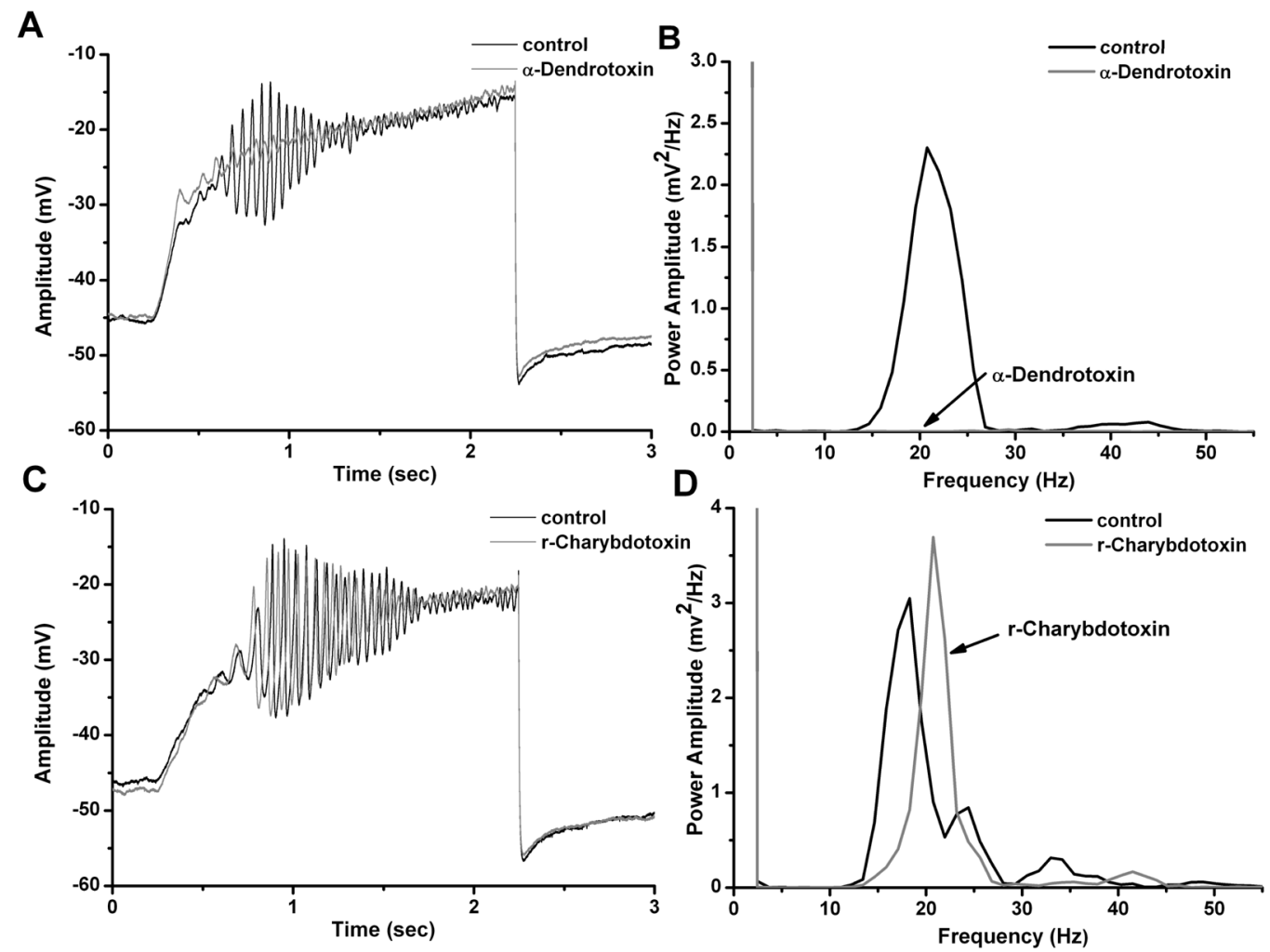

Figure 4. Delayed rectifier-like potassium channels mediated the repolarizing phase of gamma band oscillations in PPN

Gamma band oscillations induced by 2 sec-long current clamp ramps were blocked by the delayed rectifier $\mathrm{K}^{+}$channel blocker a-Dendrotoxin $(2 \mu \mathrm{M})$. A) Membrane oscillations in control (black record) recordings were blocked by a-Dendrotoxin (gray record). B) Power spectrum showing that power amplitude at gamma band frequency was blocked by $a$ -

Dendrotoxin. C) 2 sec-long ramps during control (black record) and after r-Charybdotoxin (200 nM) application (gray record). D) Power spectrum showing power amplitudes of rampinduced oscillation during control (black peak), and during r-Charybdotoxin application (gray peak). Note the slight increase in amplitude and small shift towards higher frequencies after r-Charybdotoxin application. 

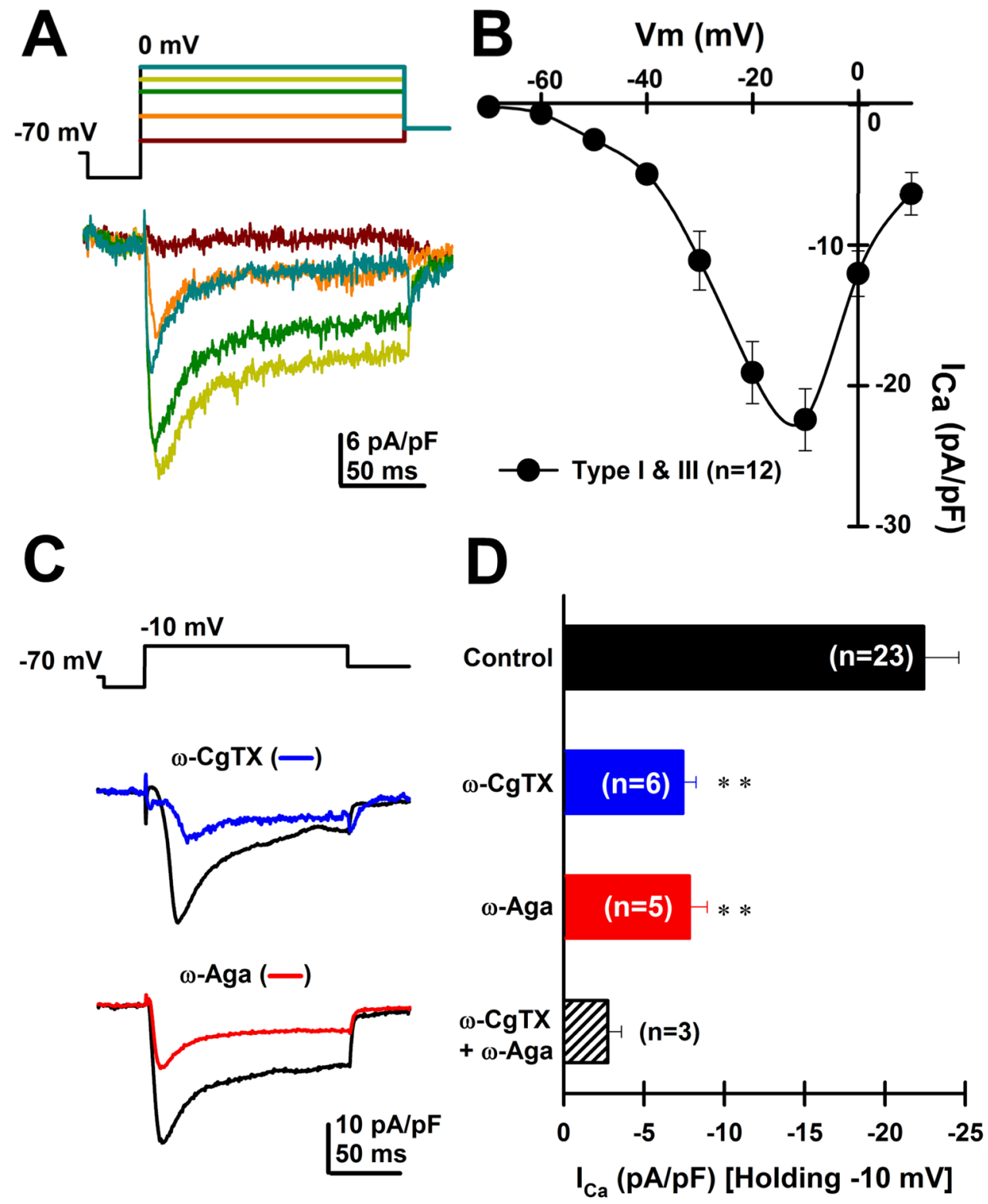

Figure 5. Both N-type and P/Q-type calcium channels are present in PPN neurons A) Representative calcium currents obtained using a depolarization protocol (see text). B) Average current-voltage (I-V) curve showing both low voltage- (T-type) and high voltageactivated calcium currents in type I and III PPN neurons $(n=12)$. C) Representative calcium currents obtained at $-10 \mathrm{mV}$ holding potential (see above protocol) before (black records), and after either $\omega$-CgTX (2.5 $\mu \mathrm{M}$; blue record), or $\omega$-Aga (100-200nM; red record).

Control calcium current records were obtained from two different type I or III PPN neurons.

D) Calcium current density values (measured at a holding potential $-10 \mathrm{mV}$ ) in control condition (black bar), and in the presence of either $\omega$-CgTX (blue bar), $\omega$-Aga (red bar), or both (dashed bar). **, $P<0.01$, Student's t-test, comparing channel blocker groups vs. control group. 

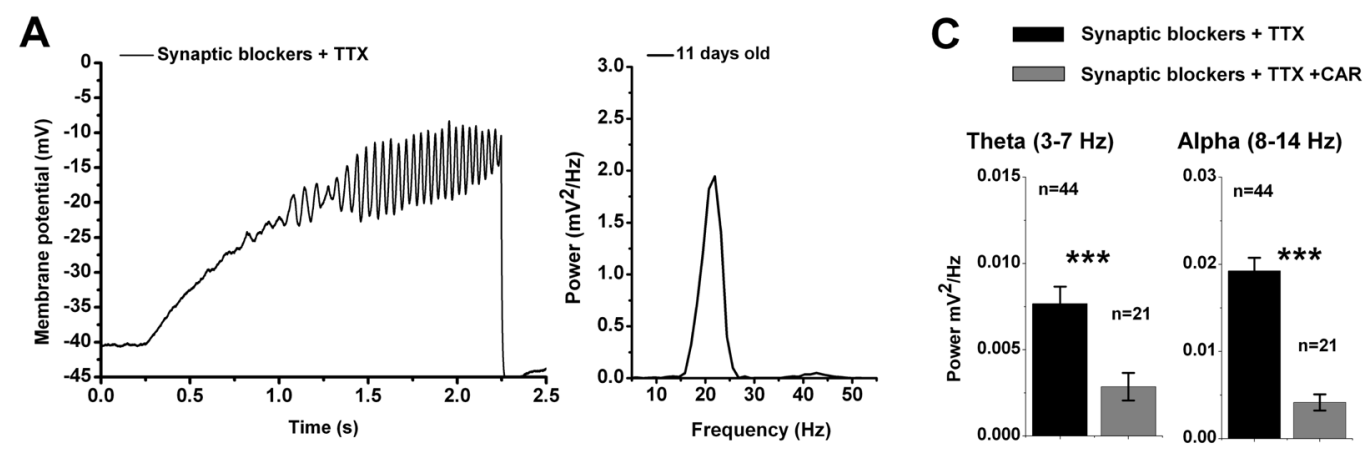

B
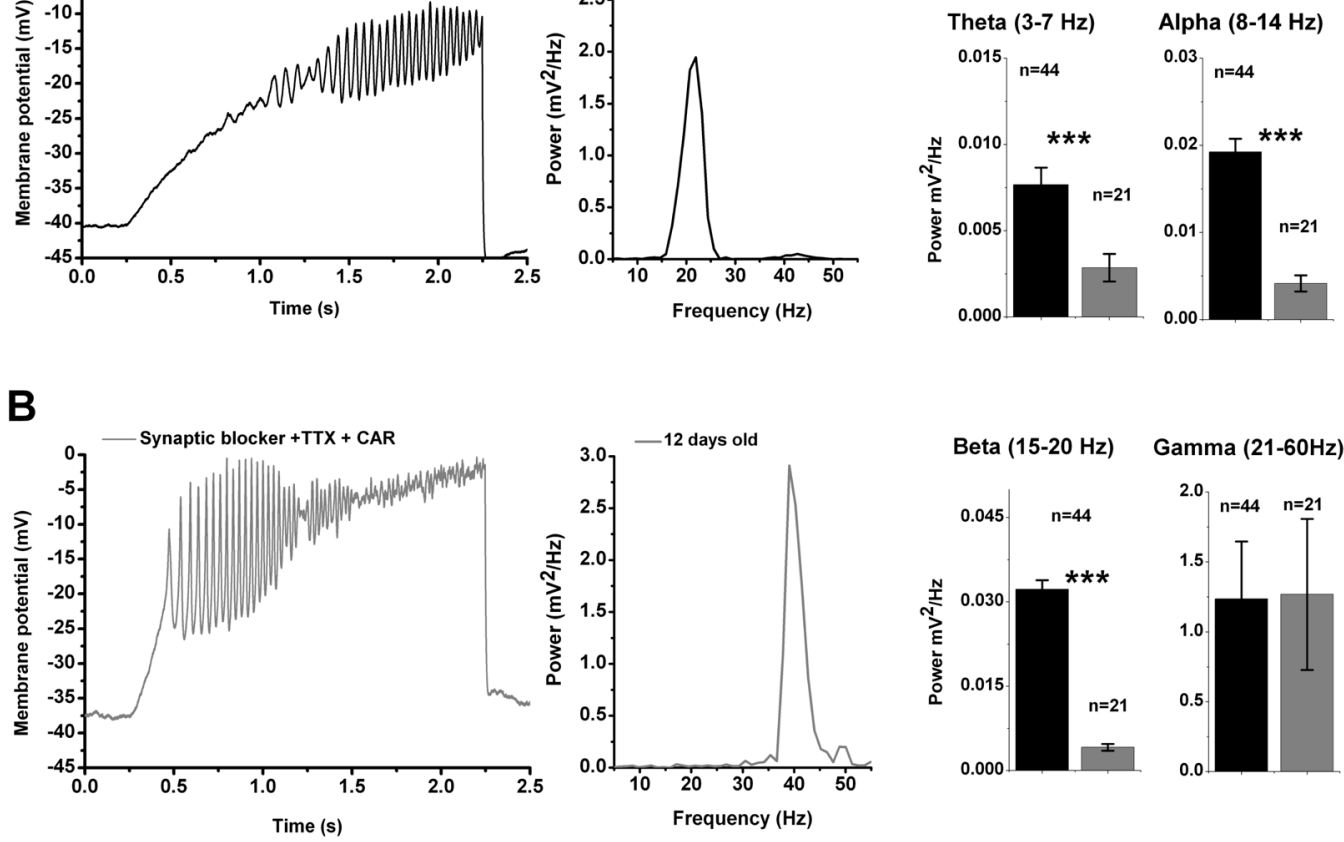

Figure 6. Carbachol increased the maximum frequency of gamma oscillations in all three types of PPN neurons

A) Example of oscillating PPN neuron (11 day old) in the presence of synaptic blockers (APV $40 \mu \mathrm{M}$, CNQX $10 \mu \mathrm{M}$, STR $10 \mu \mathrm{M}$, and GBZ $10 \mu \mathrm{M}$ ) and TTX during 2 sec ramp protocol on the left, and power spectrum on the right. B) Example of oscillating PPN neuron (12 day old) in the presence of synaptic blockers, TTX, and CAR $(30 \mu \mathrm{M})$. Note the almost doubling in frequency on the power spectrum on the right $(\sim 40 \mathrm{~Hz}$, gray) compared to PPN neuron recorded in the presence of only synaptic blockers and TTX ( 21Hz, black). C) Bar graphs of average power amplitudes at different frequency ranges. Note the reduction in power amplitude at lower frequencies (theta, alpha and beta) but not at gamma band under CAR perfusion. $* * *, P<0.001$, ANOVAs comparing no CAR group vs. CAR group 

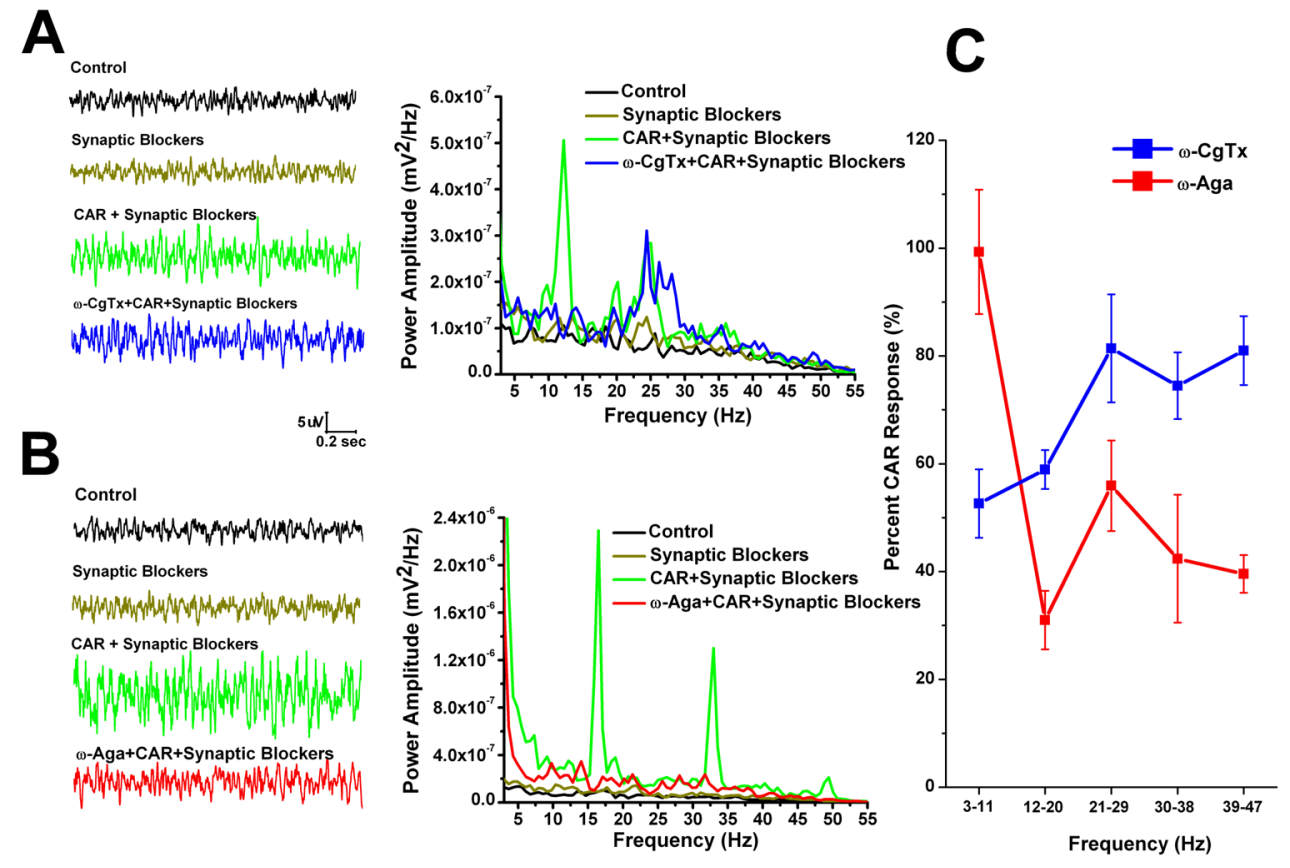

Figure 7. P/Q-type and N-type $\mathrm{Ca}^{2+}$ channel blocker effects on $\mathrm{CAR}$-induced population responses in the PPN

A) Power spectrum of population responses recorded during control (black record and line), 4 min after superfusion of synaptic blockers (APV $40 \mu \mathrm{M}$, CNQX $10 \mu \mathrm{M}$, STR $10 \mu \mathrm{M}$, and GBZ $10 \mu \mathrm{M}$, brown record and line), 9 min after CAR $(50 \mu \mathrm{M})$ superfusion in the presence of synaptic blockers (green record and line), and 10 min after $\omega-\mathrm{CgTx}$, in the presence of CAR and synaptic blockers (blue record and line). Note the decrease in amplitude of population responses at lower frequencies, while there was little effect on the higher frequencies $(>20 \mathrm{~Hz})$. B) Power spectrum of population responses during control (black record and line), 4 min after superfusion of fast synaptic blockers (brown record and line), 8 min after superfusion of CAR in the presence of fast synaptic blockers (green record and line), and $8 \mathrm{~min}$ after superfusion of CAR, fast synaptic blockers, and $\omega$-Aga (200 nM, red record and line). Note the elimination of frequencies higher than theta by $\omega$-Aga. C) Graph of percent of CAR response after specific calcium channel blockers vs. frequency. Note how $\omega$-Aga (red line) blocked higher frequencies $(12-47 \mathrm{~Hz})$ and not lower ones $(3-11 \mathrm{~Hz})$, while $\omega$-CgTx (blue) more effectively blocked lower frequencies rather than the higher ones. 
Table 1

Effects of carbachol (CAR, $30 \omega \mathrm{M})$ on gamma band oscillations in PPN neurons

\begin{tabular}{|c|c|c|c|c|}
\hline & \multicolumn{3}{|c|}{ Mean + SE } & \\
\hline & Avg. Freq. of highest peaks $(H z)$ & $\operatorname{Rin}(\mathbf{M} \Omega)$ & $\mathbf{C f}(\mathbf{p F})$ & $(\mathbf{n})$ \\
\hline No CAR & $23+/-1$ & $165+/-9$ & $34.7+/-1.9$ & 42 \\
\hline CAR & $47+/-2$ & $207+/-15$ & $30.1+/-1.6$ & 20 \\
\hline One-way ANOVA & $\mathrm{p}<0.001$ & $\mathrm{p}=0.02$ & $\mathrm{p}=0.24$ & \\
\hline
\end{tabular}

Rin- input resistance; Cf- capacitance; values- mean +/- SE. 